\title{
UMA LEITURA SOBRE A POLÍTICA DE AVALIAÇÃO E A ABORDAGEM DA OBRA DE ARTE COMO ENTRELUGAR MEDIATÓRIO DE UMA INTERVENÇÃO DISCURSIVA
}

\author{
Maria Cristina Rezende de Campos \\ Secretaria Municipal de Educação, Ciência e Tecnologia - SEMECT \\ Fundação Municipal de Educação de Niterói - FME
}

\begin{abstract}
Resumo
Neste ensaio tenciono provocar uma reflexão sobre o descentramento do sujeito, enquanto agente de uma política compreendida como produção discursiva. Proponho ensaiar movimentos de escape, nas fissuras de um exterior constitutivo de crise da qualidade da educação, tendo como referência as cadeias de equivalência abordadas na teoria do discurso. Convido o leitor à fruição estética sobre a forma fluida e irregular do horizonte da política de avaliação, por intermédio da análise de indicadores de qualidade, apresentando como metodologia o entrelugar mediatório da obra de arte, como intervenção discursiva em diálogo com a pesquisa teórico-bibliográfica e documental. Concluo argumentando que a política de avaliação da Rede Municipal de Educação de Niterói, apurada por seus indicadores de qualidade locais, tem se apresentado como uma superfície disjuntiva, engendrada no terreno do indecidível e do imprevisível de cadeias de equivalência, formadas em territórios de disputas - uma prática articulatória discursiva que se dá na lógica da negociação e da enunciação.
\end{abstract}

Palavras-chave: Política de avaliação. Prática articulatória. Intervenção discursiva.

\begin{abstract}
In the present essay, I intend to instigate a reflection on the decentralization of the subject, as an agent of a certain policy, taken as a discursive production. I suggest the testing of escape movements in the fissures of an exterior constitutive of the crisis of the education quality, using as a reference the equivalence chains as approached in the discourse theory. I invite the reader to an aesthetic fruition over the fluid and irregular form of the evaluation policy horizon through the analysis of quality indicators, presenting as methodology the intermediative in-between of the work of art, as a discursive intervention the dialogs with theoretical-bibliographic and documentary research. I conclude stating that the evaluation policy of the Municipal Education System of Niterói, according to their local quality indicators, has been presenting itself as a disjunctive surface, engendered in the realm of the undecidable and unpredictable of the equivalence chains formed territories of disputes - an articulatory discursive practice taken under the premises of negotiation and enunciation.
\end{abstract}

Key words: Evaluation policies. Articulatory practice. Discoursive intervention. 


\section{Leitura inicial}

A política de avaliação no Brasil, desde os anos 90, tem como premissa fomentar condições que propiciem a melhoria da qualidade da educação, assim como a garantia do processo de gestão e de democratização das instituições, mobilizando discussões acerca desse entendimento. Em sua tarefa de fixar sentido para a qualidade da educação, os discursos hegemônicos a tomam como um ponto nodal, resultante de uma prática articulatória capaz de sobredeterminar as demandas de diferentes atores sociais, constituindo-se nesse jogo político como uma disputa alongada e desdobrada, visto que são hegemonizadas em outras articulações que não cessam de acontecer. A prática articulatória, considerada como uma objetivação de um significante, estruturada em torno de um lugar vazio a ser permanentemente preenchido, constitui-se em um elemento de convergência que aglutina diversas demandas no campo da discursividade. $\mathrm{O}$ que se supõe estabilizado é submetido à tradução, segundo Lopes (2018a):

A norma constituída hegemonicamente, entretanto, não pode ser transformada no autoritarismo que visa a garantir o cumprimento da norma. A continuidade da política e a multiplicação dos centros de poder, nessa perspectiva, são o que se pode manter aberta a negociação democrática sobre a normatividade que visa a constituir o social de certa maneira (p. 162).

Nessa perspectiva, a qualidade da educação não deve ser regulada por modelos e técnicas prescritas em nome da eficiência dos processos educativos - por meio de novas práticas pedagógicas, novos conteúdos, novos modelos de gestão da institucionalidade, novas formas de aferição da aprendizagem -, enquanto projeto supraideológico, supraclassista, de produção de sujeitos livres e competentes ou críticos, atribuindo-se à educação o lugar universal de sutura das múltiplas falhas da ordem capitalista e/ou democrática em assegurar a igualdade de direito a todos (Burity, 2010).

Ao propor uma leitura da política de avaliação, tendo como entrelugar mediatório a obra de arte, enfatizo o exercício dessa abordagem pelo gozo do "olhar entre" os modos de ser e significar a posição humana atinente à discursividade, cuja significação é contingente, provisória e precária. O filósofo indiano Homi Bhabha (2012) argumenta que a arte tem a capacidade de revelar o quase impossível, entre o extático e o cotidiano, a fim de encontrar uma linguagem para os altos horizontes da própria humanidade e para revelar a sua própria fabulação, a sua fragilidade, no momento de sua articulação. Assim, a obra de arte pode ser a ponte entre a "aura", associada ao sublime, e a "ágora", lugar de inscrição temporal dos sujeitos no mundo prosaico do cotidiano, "ao insistirmos em que ambos os estados do ser e do significar deveriam se confrontar com a alteridade ou os limites de seus campos discursivos" (Idem, p. 97-98).

Entre a aura e a ágora, tenciono neste ensaio ${ }^{1}$ experimentar a negociação do gozo pela intervenção discursiva, que emana da leitura da obra de arte em uma aproximação com a leitura sobre a política de avaliação, expondo sua flutuação de sentidos em seus processos de 
significação. O gozo como fruição estética de um sublime sequestro e a negociação como um ruído na prática cotidiana, escolhendo-se como mediação a obra de arte, mais especificamente, a Tira de Moebius II (Fig. 1) do artista holandês Maurits Cornelis Escher², provocando uma reflexão sobre o descentramento do sujeito, enquanto agente de uma política, compreendida como prática articulatória e produção discursiva.

Fig. 1 - Tira de Moebius de Escher, 1960.

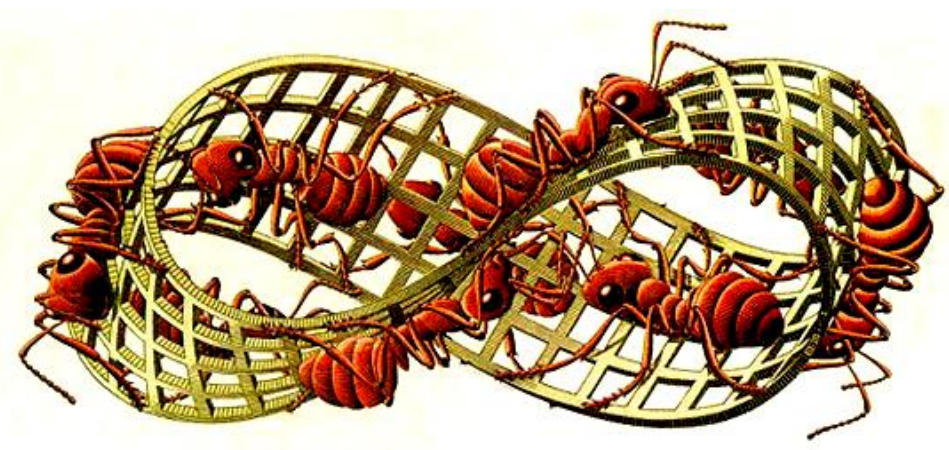

Fonte: Google imagens. Disponível em:

$<$ https://www.inovacaotecnologica.com.br/noticias/noticia.php?artigo=fita-mobiusluz\&id=010160150130\#.XD31GtJKjcc>. Acesso em: 15 de nov. 2018.

Interessa-me discutir os efeitos e os insights que pairam nas bordas do objeto de pesquisa - indicadores de qualidade da educação -, o que significa engendrar um discurso do autodesvelamento, abrindo um espaço de sobrevivência nos interstícios entre a aura e a ágora, que depende de uma compreensão da interpretação, enquanto intervenção na própria estrutura significativa do objeto.

As interpretações não são meras leituras de segunda ordem que elaboram, em atraso, alguma pura essência ou expressão que o trabalho emana ab novo, em um tipo de espontaneidade sublime. A interpretação, quase literalmente, leva o trabalho de dentro para fora: ela enuncia, até mesmo exacerba, os múltiplos campos da visualidade e as superfícies de significação que estão articuladas no trabalho (Bhabha, 2012, p. 103).

Essa enunciação dos campos de visualidade significa um "olhar entre", uma leitura nas entrelinhas do que a imagem emana. É intervenção e é proposição de leituras às superfícies discursivas que a obra do artista Escher vem a significar, abrindo a perspectiva ambivalente da ética interpretativa e da estética intervencionista que é, ao mesmo tempo, liminar e luminosa. Como o entrelugar mediatório, a obra de arte em sua capacidade tradutória põe em agonia sua própria existência, demarcando e redemarcando as fronteiras materiais da diferença, articulando "lugares" onde a questão da "especificidade" é ambivalente e complexamente construída (Bhabha, 2012). 
É a partir desse espaço-tempo elidido que a intervenção da interpretação se torna a teia da comunicação e da comunidade, a ágora da posição humana delineada em sua discursividade. Nessa perspectiva, apresento uma aproximação entre Bhabha, Laclau e Mouffe, na compreensão de política como prática articulatória em constante negociação, considerando suas contribuições para a interpretação da obra de arte, enquanto intervenção discursiva na política de avaliação.

Trilhando o caminho da desconstrução de uma imagem fixa da superfície da educação, anuncio um olhar sobre o fluxo pulsional de uma superfície flutuante e cambiante, representada pela Tira do Infinito de Moebius, cujas formigas-sujeitos se posicionam em movimentos de articulação e negociação de suas diferenças. Proponho um olhar por dentro da tira no infinito, ao intervir na obra de Escher, ensaiando movimentos de escape nas fissuras de um exterior constitutivo de crise da qualidade da educação, tendo como referência a prática articulatória em cadeias discursivas proposta na teoria do discurso, desenvolvida por Laclau e Mouffe. Convido o leitor à fruição estética sobre a forma fluida e irregular do horizonte da política de avaliação, por intermédio da análise de indicadores de qualidade, no âmbito da Secretaria Municipal de Educação, Ciência e Tecnologia/Fundação Municipal de Educação de Niterói (SEMECT/FME), bem como do Instituto Nacional de Estudos e Pesquisas Educacionais Anísio Teixeira (INEP), apresentando como metodologia o entrelugar mediatório da obra de arte, como intervenção discursiva para a interpretação que desenvolvo a seguir, em diálogo com a pesquisa teórico-bibliográfica e documental.

\section{O fantasma da crise da educação e seus indicadores de qualidade}

Podemos visualizar o anunciado fantasma da crise da educação, por intermédio do baixo índice da educação pública, apontado pelo Índice de Desenvolvimento da Educação Básica $(\mathrm{IDEB})^{3}$, servindo como exterior constitutivo à produção de hegemonias, formadas por demandas de qualidade da educação, constituindo-se em diferentes paisagens, impondo um novo modelo de governança que se articula com as perspectivas das instituições e organizações privadas - as salvacionistas. Uma rede privada de parceiros que visa à expulsão das antigas formas de gestão da educação como bem público, uma hegemonia da nova forma de sociabilidade em defesa da centralização de conteúdos, de direitos de aprendizagem, de padrões de avaliação (Macedo, 2014).

Imersa no campo da educação, especificamente na leitura de indicadores educacionais da Rede Municipal de Educação de Niterói ${ }^{4}$, desde 2009, venho analisando os efeitos dessa política de resultados na prática cotidiana dos profissionais da educação, no que se refere às normas instituídas hegemonicamente acerca da melhoria da qualidade da educação, fixada no aumento do IDEB, medido pelo desempenho dos estudantes em avaliações de larga escala e pela fixação de estratégias de responsabilização e controle. Percebi, durante esse período, bastante desconforto por parte de professores e diretores de escolas, tanto pela associação da qualidade da educação aos resultados das avaliações por parte dos gestores municipais, dos representantes políticos e da comunidade jornalística, quanto pela desconsideração de 
indicadores contextuais que influenciam na aprendizagem dos (as) estudantes como: relações interpessoais, organização administrativa e pedagógica da escola, infraestrutura física, número de profissionais adequados à realidade de cada escola, participação dos responsáveis na rotina escolar dos (as) estudantes, violência no entorno da comunidade escolar, por exemplo.

O IDEB, como um significante vazio, tornou-se ponto nodal de condensação de múltiplas demandas, consideradas como indicativos de qualidade da educação. Um significante vazio que representa um sistema de significações polissêmico, sendo um princípio articulador de uma cadeia de equivalências, que determina e auxilia a/na execução de políticas públicas voltadas para a melhoria da aprendizagem dos (as) estudantes, conforme a meta 7 fixada no Plano Nacional de Educação, 2014-2024:

Fomentar a qualidade da educação básica em todas as etapas e modalidades, com melhoria do fluxo escolar e da aprendizagem, de modo a atingir as seguintes médias nacionais para o IDEB: 6,0 nos anos iniciais do ensino fundamental; 5,5 nos anos finais do ensino fundamental; 5,2 no ensino médio (Brasil, 2014, s/d).

Para o alcance das metas projetadas até 2021, o governo federal estabeleceu estratégias, as quais destaco: implantar uma base nacional comum dos currículos para a educação básica; constituir um conjunto de indicadores de avaliação institucional; induzir processo contínuo de autoavaliação das escolas; formalizar e executar planos de ações articuladas voltadas à melhoria da gestão educacional, à formação de professores (as) e profissionais de apoio, à ampliação e ao desenvolvimento de recursos pedagógicos e à melhoria e expansão da infraestrutura física da rede escolar; estabelecer políticas de estímulo às escolas que melhorarem o desempenho no IDEB, de modo a valorizar o mérito de seus profissionais, entre outras (Brasil, 2014).

As políticas concebidas nesse registro supõem uma igualdade de propósitos imune à tradução, ao ato de diferir. Ou seja, perspectivas prescritivas, ou mesmo propositivas, com base em fundamentos fixos, cujos "sujeitos são plasmados por uma agência que implica responsabilidade por decisões tomadas em terrenos indecidíveis, assumindo seu caráter faltoso, incompleto, radical" (Lopes, 2018a, p. 136). Ou ainda, "é a política do mútuo esforço da semelhança e da diferença para se canibalizarem reciprocamente, assim proclamando o saque vitorioso das ideias gêmeas do Iluminismo, o universal triunfalista e o particular resiliente" (Appadurai, 2004, p. 63).

Dessa forma, ao se considerar a hegemonia como contingente, há uma impossibilidade de fechamento cuja formação discursiva não é dada e delimitada, não sendo possível haver nem uma interioridade nem uma exterioridade total, campo da sobredeterminação onde as identidades nunca conseguem ser plenamente fixadas (Laclau; Mouffe, 2015). Aparentemente, um processo regido por uma lógica dual, polarizada. Porém, em outro entendimento, um processo que abriga disputas, articula discursos vários e cria um híbrido de diferentes posições de sujeito, operando em uma cadeia de equivalências entre discursos universalistas em negociação com as demandas da diferença (Burity, 2010; Macedo, 2014). 
Nesse campo de disputas, os profissionais que atuam na Rede Municipal de Educação de Niterói vêm criando estratégias híbridas para o enfrentamento da proclamada crise da educação e das determinações legais. Por iniciativa dos gestores municipais é instituído, em 2013, um Sistema de Avaliação da Educação de Niterói (SAEN), uma política de avaliação institucional que tem buscado a reflexão constante sobre diferentes aspectos institucionais que se interligam e colaboram com a aprendizagem dos estudantes.

Este sistema foi regulamentado pela Portaria Conjunta SEMECT/FME no 005/2015, sendo composto por quatro dimensões de análise, que orientam as políticas públicas da SEMECT, a saber: Gestão das Aprendizagens, Gestão da Rede Municipal, Gestão do Trabalho Pedagógico e Gestão Escolar. As dimensões de análise são acompanhadas por uma equipe técnico-pedagógica - Assessoria de Avaliação Institucional - composta por professores efetivos da rede.

A Gestão das Aprendizagens tem desenvolvido análises sobre a aprendizagem dos (as) estudantes do Ensino Fundamental e o contexto em que estão inseridos, através de uma avaliação diagnóstica e de um indicador contextual socioeducativo, bem como proposto ações de consolidação das aprendizagens (classes de aceleração, progressão parcial e reforço escolar) e acompanhamento da situação escolar, por intermédio de um sistema de geração de dados trimestrais, disponibilizado às equipes pedagógicas que atuam nas escolas e na sede. $\mathrm{Na}$ Gestão da Rede Municipal, há o acompanhamento do trabalho proposto pelas equipes técnico-pedagógicas da Secretaria, que inclui metas e estratégias para o assessoramento de programas e projetos a serem desenvolvidos junto às escolas. A Gestão do Trabalho Pedagógico conta com o oferecimento, por parte das equipes da sede, de um Programa de Formação Continuada, tendo em vista demandas oriundas das escolas e da análise de relatórios, assim como do acompanhamento do Projeto Político Pedagógico e do Plano de Ação, propostos pelas unidades escolares. Na Gestão Escolar, a ênfase se dá na constituição de um processo de autoavaliação, a partir de indicadores de qualidade locais, construídos pela comunidade educativa, que orientam o plano de ação de cada escola, sendo estes de acordo com seu contexto socioeducativo, tendo as seguintes linhas de análises/atuação: relação escola-comunidade, relações interpessoais, relação escola-sede, práticas pedagógicas, administração escolar e gestão pedagógica, aprendizagem/interações e brincadeiras.

No âmbito de cada gestão, instrumentos têm sido construídos e reconstruídos, conforme o andamento do processo e a contribuição dos participantes que atuam nas escolas da rede, tendo em vista que a participação dos profissionais é considerada, pelos gestores do SAEN, fundamental para a constituição do Sistema. Há que se considerar que ações propostas pelo SAEN vêm dialogando e se articulando com as demandas propostas pelo governo e com as ações propostas pelos profissionais que atuam nas escolas, em seu movimento de resistência propositiva. Tal movimento inclui a intervenção discursiva dos profissionais da rede em: análises dos indicadores externos e proposição de indicadores locais em conselhos de avaliação promovidos pelas escolas; exposição de seus posicionamentos em relatórios de devolutivas, em reuniões com setores do governo, bem como em fóruns acerca das situações 
extraescolares que influenciam na aprendizagem dos estudantes como a violência, a participação dos responsáveis, a infraestrutura física e de pessoal, entre outras.

Cabe ressaltar que as análises e avaliações propostas institucionalmente (SAEN, INEP) não são compreendidas por alguns profissionais das escolas, como proposições que colaborem com o processo educativo, conforme se observa em suas falas:

Fala 1 (...) No ano da Prova Brasil fizemos um estudo dos descritores, dialogamos com os professores e tiramos o $1^{\circ}$ lugar no IDEB de Niterói, mas o que ganhamos com isso?

Fala 2 (...) Tudo o que se fala nas avaliações acaba reverberando contra nós, daí o receio de se manifestar. Mistura de receio com descrédito.

Fala 3 (...) Não vai dar em nada. Mas até que ponto as pessoas querem se comprometer? Assumir corresponsabilidade?

(Depoimentos de diretores e pedagogos da rede em fóruns de discussão, maio de 2018).

Ou ainda, como proposições que necessitam de maior envolvimento e participação na construção coletiva das políticas de avaliação.

Fala 4 (...) Necessidade de harmonizar as relações. Necessidade de negociações, pois pensar em harmonia e consenso é utopia. Como interagir? Há um terceiro lugar que não é dado, é construído coletivamente e é híbrido.

Fala 5 (...) Necessidade de dar sentido à autoavaliação, para haver participação na execução das ações. Mudou a participação quando entenderam que o instrumento de avaliação seria criado e avaliado por eles. Então perguntaram: "Não é para a FME?". A construção coletiva dos instrumentos é necessária. (Depoimentos de diretores e pedagogos da rede em fóruns de discussão, maio de 2018).

Essa flutuação de sentido, efeito de uma prática articulatória do constante diferir, movimenta fluxos argumentativos conflituosos na formação das cadeias de equivalência. Equivalência que permite a articulação das diferenças que se encontram imbricadas e em constante tensionamento, de forma mutuamente constitutiva. Nessa perspectiva, organizar projetos educativos e fazer valer o que supomos "ser melhor" deve ser pensado como articulado à mudança social, sendo seu julgamento sempre aberto a contestações, inserido em uma política que pressupõe negociar com o outro (Lopes, 2018a).

Caminha-se, assim, para a concepção de política como um ato de enunciação, uma ação contingente, conflituosa, cujas intencionalidades e práticas discursivas buscam atribuir sentido, num universo democrático-pluralista completo de lutas e negociações (Frangella; Barreiros, 2008).

Nesse caminho conflituoso de intervenções, análises e proposições, o IDEB do município de Niterói (Fig. 2), tem demonstrado crescimento progressivo em suas taxas: de 4.4, em 2007, para 5,4, em 2017, nos anos iniciais do Ensino Fundamental; de 3,8, em 2007, 
para 4,2, em 2017, nos anos finais. Apesar das metas projetadas não terem sido atingidas, a educação pública de Niterói manteve o $3^{\circ}$ melhor IDEB nos anos iniciais da Região Metropolitana e houve o avanço do $5^{\circ}$ para o $3^{\circ}$ melhor IDEB desta mesma região, nos anos finais. Destaca-se que o aprendizado, visto por essa lente, tem crescido, conforme observado nas últimas medições: nos anos iniciais, a nota padronizada da Prova Brasil que, em 2013, era 5,39 passou para 6,1 em 2017; nos anos finais, em 2013, era 4,27 e passou para 5,01.

Fig. 2 - IDEB de Niterói

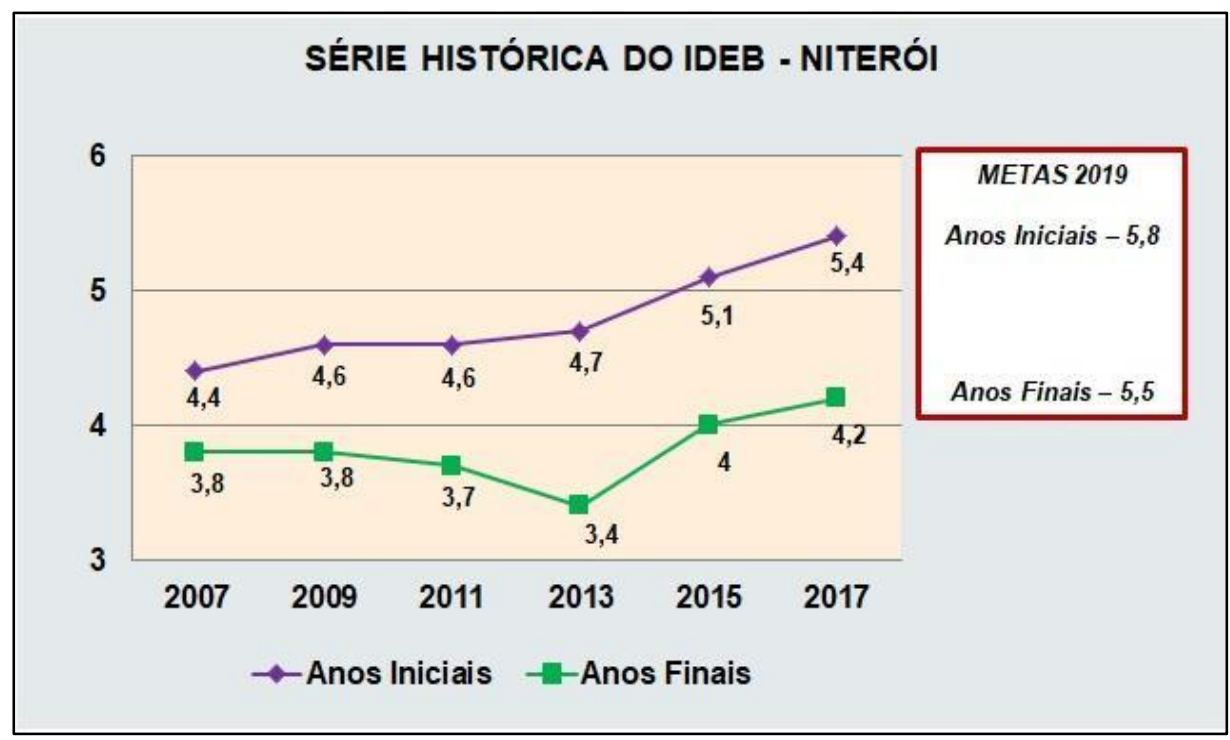

Fonte: INEP, 2018. Disponível em: <http://portal.inep.gov.br/web/guest/inicio>. Acesso em: 14 de jan. 2019.

Certamente, os índices apresentados não refletem todo o processo educativo realizado nas unidades escolares, porém revelam uma situação de aprendizado específica que tem servido para leituras, interpretações e traduções, tanto para as equipes pedagógicas que atuam na sede, quanto para as que atuam nas escolas. Destaco que a fórmula utilizada para a mensuração do IDEB é o resultado da taxa de rendimento (aprovação, reprovação, abandono escolar), obtida a partir da informação disponibilizada pelos gestores das escolas na segunda etapa do censo escolar, referente à situação escolar dos estudantes durante o ano letivo, o que significa dizer que é um resultado produzido na/pela escola. Tem servido, sobretudo, para provocar tensionamentos e estranhamentos, abalando e desestabilizando o lugar universal pensado para a qualidade da educação. Um pluralismo agonístico que mobiliza paixões em prol dos desígnios democráticos, rompendo com a representação simbólica da sociedade como um corpo orgânico e abrindo caminho para o dissenso ou, ainda, para o consenso conflituoso (Mouffe, 2005).

Assim como a Tira de Moebius de Escher, que apresenta um objeto com formigas caminhando sobre uma superfície não orientável, as demandas por qualidade da educação 
expressas em indicadores encontram-se, também, nessa superfície flutuante e cambiante de um exterior constitutivo, representado pela crise da educação pública, que articula em uma cadeia de equivalências demandas da diferença. As nove formigas grandes que caminham na torção da Tira de Moebius estão aparentemente em lados diferentes da tira, porém se seguirmos seu caminho, nos deparamos em um mesmo lado. O lado direito e o avesso ficam unidos por um ponto de vista topológico, em uma investigação da relação do espaço e sua representação sobre uma superfície. E ao continuarmos o caminho das formigas nos deparamos com a impossibilidade finita e fixa que a imagem sugere. As formigas-sujeitos ao seguirem no trilho verificam que o percurso é infinito e que ao percorrê-lo veem sua imagem refletida do avesso, como num espelho. Em sua inquietude, elas/eles perseguem seus desejosdemandas, cruzam trilhos e se encontram no lugar fronteiriço, na sobredeterminação das cadeias de equivalências. Demandas que rompem o círculo e se desdobram no seu comprimento, revirando-o e produzindo faces torcidas, indicando a não polarização, ou seja, que não há lado de dentro ou de fora, nem um nem outro.

A representação de imagens que remetem ao infinito marcou as gravuras de Escher e seu discurso. Em um artigo publicado em 1959, citado por Bruno Ernest, o artista diz:

Não podemos imaginar que algures por detrás da estrela mais longínqua do céu nocturno, o espaço possa ter um fim, um limite para além do qual nada mais existe. O conceito de vácuo diz-nos ainda alguma coisa, pois um espaço pode estar vazio, de qualquer maneira na nossa fantasia, mas a nossa força de imaginação é incapaz de apreender o conceito de nada no sentido de ausência de espaço. Por isso nos agarramos a uma quimera, a um além, a um purgatório, a um céu e a um inferno, a uma ressurreição ou a um nirvana que de novo têm de ser eternos no tempo e infinitos no espaço, e isto, desde que o homem na Terra se deita, senta ou levanta, desde que nela se arrasta e corre; navega, cavalga e voa - e da Terra para fora se projeta (Escher apud Ernest, 1991, p. 102).

A estética discursiva de Escher marca o fluxo pulsional de uma superfície flutuante e cambiante, representada pela tira do infinito e sua projeção no espaço vazio que se preenche contingencialmente, num constante movimento do porvir. Em uma interpretação lacaniana, Tania Rivera (2008) argumenta que a arte moderna surge no mesmo momento da psicanálise, quando convoca o sujeito a se reconstituir, assujeitado não mais a um espaço pacífico, mas vertiginoso. À maneira como o inconsciente freudiano subverte o sujeito, o psicanalista Lacan faz uso da fita de Moebius ao levar em consideração os objetos que subvertem a representação do espaço que põem a imaginação ao avesso. A superfície trata-se da projeção do corpo, casa imaginária que não tem senhor: revira-se então a imagem e seu referente, e o "eu" torna-se fita moebiana, superfície unilateral, sem distinção entre dentro e fora, punção que indica as relações com a alteridade. Não há espelho capaz de construir uma imagem constante, como argumenta Rivera (2008): 
Não há mais garantia suprema de estabilidade entre os termos da representação, mas reconhecimento de um olhar que, de fora, faz o sujeito tropeçar e, deixando sua posição de senhor magnânimo da representação, ser olhado (s/p).

Anuncia-se a morte de um sujeito que se situa em um ângulo que se assemelha ao centro da vida. De sujeito magnânimo ele se torna agente assujeitado a um outro olhar, a um olhar do Outro. Na ausência dessa dialética do dentro/fora e da sua metafísica da profundidade, Bhabha (2012) enuncia que a "teia das relações humanas" emerge no momento intersticial e elíptico em que a narrativa da história humana revela um agente, um sujeito que é o ator e o receptor. Nessa relação indeterminada, o filósofo ressalta o desafio ético e estético de viver em paisagens temporais disjuntivas que nos direcionam a reestruturar o passado, de forma que a história do presente possa engendrar as possibilidades do futuro como uma questão aberta, uma negociação com as paixões e com as ciladas da liberdade (Idem).

Viver em paisagens temporais requer uma leitura sobre a política de avaliação com um campo discursivo de uma prática articulatória em constante negociação entre os sistemas de intercâmbio social, enquanto elocução humana, de mediar o que parece ser contraditório. Requer operar um deslocamento nas relações tradicionais de poder e democracia. Na ausência de um centro, tudo se torna discurso, como um sistema de entidades diferenciais, que amplia indefinidamente o campo e o jogo da significação. Na tentativa de deter o fluxo das diferenças, os pontos discursivos se constituem em pontos nodais, um significante que detém o deslizamento da significação, ainda que precariamente e contingencialmente, de demandas particulares que se desejam universais, hegemônicas, que ao se articularem criam as cadeias de equivalência.

Nesse campo de disputas, de constante trasbordamento de todo discurso, pela sua própria infinitude, a prática articulatória cria cadeias de equivalências cujos pontos nodais fixam sentidos parciais. Ou seja, a articulação discursiva se dá via processo de mobilização social, que engloba duas lógicas: a da equivalência e a da diferença, sendo a lógica da diferença um processo que abarca algo construído na exterioridade (exterior constitutivo), em uma espécie de fechamento momentâneo do sistema (cadeia de equivalência) e, a lógica da diferença se pauta na premissa de que o fechamento seria inviável, tornando-a um campo de significação fluido, ambíguo e temporário (Frangella; Barreiros, 2008).

Esse caráter flutuante e ambíguo do significante penetra a identidade discursiva (social) na medida de uma proliferação de significados, desarticulando sua estrutura discursiva (Laclau; Mouffe, 2015):

A prática de articulação, portanto, consiste na construção de pontos nodais que fixam sentido parcialmente; e o caráter parcial desta fixação advém da abertura do social, resultante por sua vez, do constante transbordamento de todo discurso pela plenitude infinita do campo da discursividade (Idem, p. 188).

Nesse campo da discursividade, a tira moebiana em seu fluxo contínuo, em seu desejo de continuar desejando, de seguir encontrando e desencontrando, ressalta a teia das relações 
dos sujeitos e seus modos de articulação, contorcendo-se e constituindo-se em complexo campo relacional, cuja particularidade preenche parcial e temporariamente o lugar vazio do universal, o que implica o caráter político. Tal processo, segundo Burity (2010), corresponde a uma prática articulatória produtora de equivalências entre posições diferentes, ao construir uma divisão social em relação a um outro antagonístico. Onde quer que a experiência antagonística ou um deslocamento no discurso hegemônico produza uma demanda articulada, estaremos na presença do político, das múltiplas e contingentes formas de estabilização de sentidos em disputa ou em fluxo social de modo a produzir efeitos de ordem. "É esta ambiguidade que torna possível a articulação como uma prática instituinte de pontos nodais, que fixam parcialmente o sentido do social num sistema organizado de diferenças" (Laclau; Mouffe, 2015, p. 214). Nesse sentido, o social é resultante de infinitas disputas antagônicas, discursivas e contingentes, que se traduzem no movimento político que ocorre no campo das políticas de avaliação, que percebo ocorrer na Rede Municipal de Educação de Niterói.

Nessa superfície de constituição do social, a qualidade da educação é entendida como ato enunciativo, que acontece discursivamente num caminho sem começo e sem fim, o qual numa mesma face do trilho, em seu movimento fluido e alongado (extensão do trilho paralelas que se desdobram em perpendiculares e oblíquas à superfície), constitui-se por seus pontos de fuga (pontos nodais), fixados parcialmente (porque o sentido pode sempre vir a ser outro), com distintas direções, provocando e impulsionando o deslocamento incessante das cadeias de equivalências (Fig. 3).

Fig. 3 - Superfície flutuante da qualidade da educação

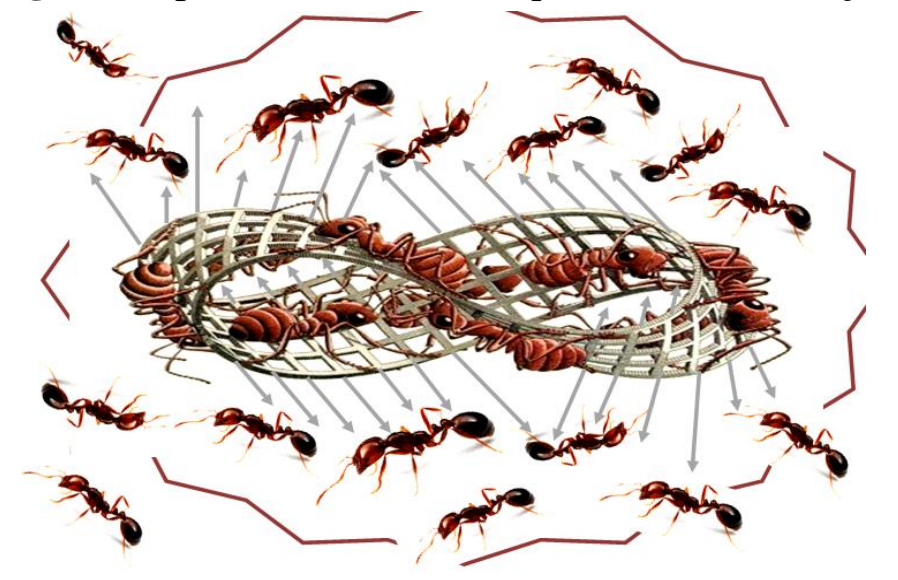

Fonte: (Re)leitura, autora, 2018.

Proponho com essa imagem intervir esteticamente na Tira de Moebius, apresentando a superfície flutuante da política de avaliação na/da educação constitutiva da enunciação intercambiante de significados acerca da qualidade da educação em disputa na Rede Municipal de Educação de Niterói, deslocados pelas demandas da diferença, pelo ato de diferir. $\mathrm{O}$ ato de diferir, segundo Derrida (2007), apresenta o duplo movimento da différance, 
do imensurável, significando que o sentido é sempre diferido por outras palavras, signo que representa o ausente na presença, que necessita negociar ou argumentar com o calculável, mas sabê-lo sempre violento, perturbando a técnica pela introdução do político, que é o lugar de uma negociação ou de um compromisso com a desconstrução, com a tradução, com o acontecimento.

Em um terreno indecidível e imprevisível de formações discursivas, as demandas educacionais em fluxo contínuo de significação (Fig. 4 e Fig. 5) impulsionam as cadeias de equivalência, em um processo de disputa agonística por sentidos. $\mathrm{O}$ entrecruzamento de linhas e fluxos traçados na torção da tira moebiana nos remete a uma imagem que revela um movimento infinito, ou do infinito, como apontado por Deleuze e Guatarri (1995), formando novos devires, fluxos que ao se encontrarem modificam seu movimento. O que implica num voltar-se, perder-se, apagar-se.

Fig. 4 - Estudo II da Superfície flutuante; Fig. 5 - Estudo III da Superfície flutuante.

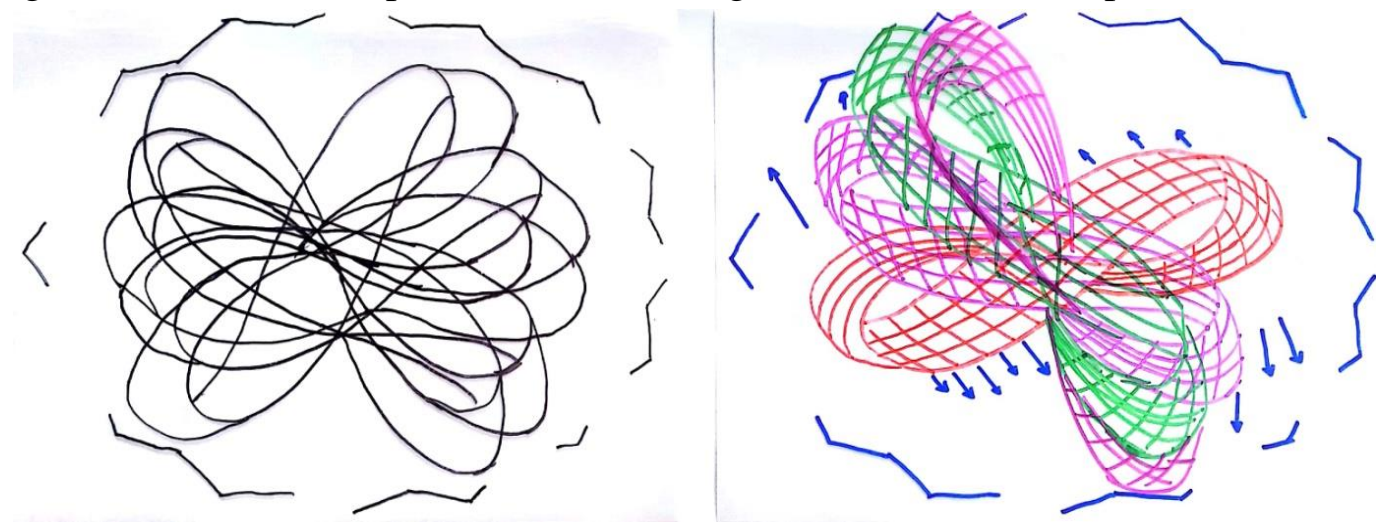

Fonte: Autora, 2018.

Ao considerarmos a possibilidade incessante de articulação de demandas da diferença, a política de avaliação se apresenta como um plano de imanências múltiplas que se abre a experimentações híbridas e contingentes, constituindo-se por seus escapes e suas linhas de fuga.

Cada movimento percorre todo o plano, fazendo um retorno imediato sobre si mesmo, cada um se desdobrando, mas também dobrando outros ou deixando-se dobrar, engendrando retroações, conexões, proliferações, na fractalização desta infinidade infinitamente redobrada (curvatura variável do plano) (Deleuze; Guattari, 1997, p.54).

Nesse sentido, a política de avaliação se constitui em uma superfície construída conforme ruptura do próprio contexto, que nunca é absolutamente determinável, sendo assim, jamais saturado, conforme análise derridiana apresentada por Lopes et al. (2013). Plano de 
consistência constituído por uma ação política que celebra o imponderável da educação - o constante porvir.

\section{Leitura final}

Considerando o contexto performático de indicadores de resultado, as políticas de avaliação ganham centralidade no planejamento de metas e estratégias para o alcance da democratização do processo educativo. Os resultados alcançados no IDEB, que buscam estabelecer uma ordem universal ao caos da educação, supõem uma "racionalidade e uma lógica que foram construídas se sobrepondo à necessidade de argumentar e negociar politicamente, com todas as dificuldades e conflitos que tais processos envolvem" (Lopes, 2018a, p.162-163). A autora aposta na possibilidade de argumentar e negociar a significação do caos, de produzir interlocução, ciente da impossibilidade de estar no lugar do outro, mas ainda assim tentando interpretar esse lugar, assumindo, desse modo, a condição demasiado humana que faz parte da compreensão de que "qualquer comunidade é produzida discursivamente na luta política. É uma comunidade sem algo em comum, sem unidade" (Lopes, 2018b, p. 84).

Nesse movimento multidirecional e descentrado, cadeias de equivalência entram em constante disputa em torno de orientações e interpretações acerca das políticas da educação. No sentido de um fluxo contínuo de pulsações, ao pensar a tira moebiana como intervenção discursiva e, portanto, política, aproprio-me da narrativa de Bhabha (2012) quando aborda a arte como possibilidade de ligação entre a aura e a ágora, entrelaçando-as e emaranhando-as. "Narrativa vista como o discurso do autodesvelamento, a produção de sujeitos e o posicionamento dos espectadores", ou ainda, "como mediação entre o silêncio sublime e o atordoamento provocado pelas visões e pelos sons do cotidiano" (Idem, p. 98).

No insolúvel cenário de crise da educação, abre-se um espaço de sobrevivência nos interstícios da política de avaliação, no entrelugar mediatório que a leitura da tira moebiana, enquanto intervenção discursiva, relegando toda forma de significação que hegemoniza as soluções em torno de demandas. Cabe-nos assim, conforme Burity (2010), a tarefa de reconstituir o processo político de constituição dos discursos hegemônicos que inscrevem a instrumentalidade da educação num horizonte de funcionamento para o/do mercado, da educação como projeto de emancipação de cidadãos (ãs) e como prática de reconfiguração do social, visto que não está determinado o conteúdo universal da educação. "O próprio do evento político é subsistir em sua emergência quase imperceptível, até que novas circunstâncias por vezes lhe conferem a chance de interromper a ordem das coisas, em meio a deslocamentos e antagonismos" (Idem, p. 26).

No esvaziamento do caminhar na trilha do infinito, do nem um nem outro, a teia das relações humanas torna-se o entrelugar da negociação do gozo, como diz Bhabha (2012) sobre esse acontecimento, citando a instalação Room Saint John of the Cross (Sala para São João da Cruz) do artista Bill Viola que repousa sobre a apreensão da posição humana. O processo de intermediação e iteração começa a acontecer. 
Ali, em um momento de folga, você o tem, o gozo da negociação. Se você o perder, vire a página, gaste dinheiro com você, puxe as cortinas ou abra a janela... Escute... Olhe... Acontecerá de novo... quando você não desejar particularmente que aconteça... quando você precisa ir a alguma parte e continua calmamente a velejar... (p. 113).

A videoinstalação de Viola estabelece uma narrativa espacial de repetição e eco, uma paisagem do acontecimento da posição humana. Da mesma forma que a paisagem fluida pintada por Monet na "Série Catedral de Rouen" (Fig. 6), que subverte a natureza ontológica de uma pressuposta homogeneidade de representação de um objeto pictórico. Assim como o cachimbo pintado por Magrite em "Traição das Imagens" (Fig. 7), no qual apõe a legenda Ceci n'est pás une pipe (Isto não é um cachimbo) contra o realismo mimético, demovendo palavras, coisas e imagens de uma pretensa clarividência e da verificação da verdade, onde nada pode se constituir em ancoragem, seja no âmbito do plano temático, do plano ótico ou do plano linguístico (Sousa; Silva, 2013). Paisagens que enfatizam a precariedade da finitude da verdade.

Fig. 6 - Catedral de Rouen, Monet, 1894; Fig. 7 - Traição das Imagens, Magritte, 1928-29.

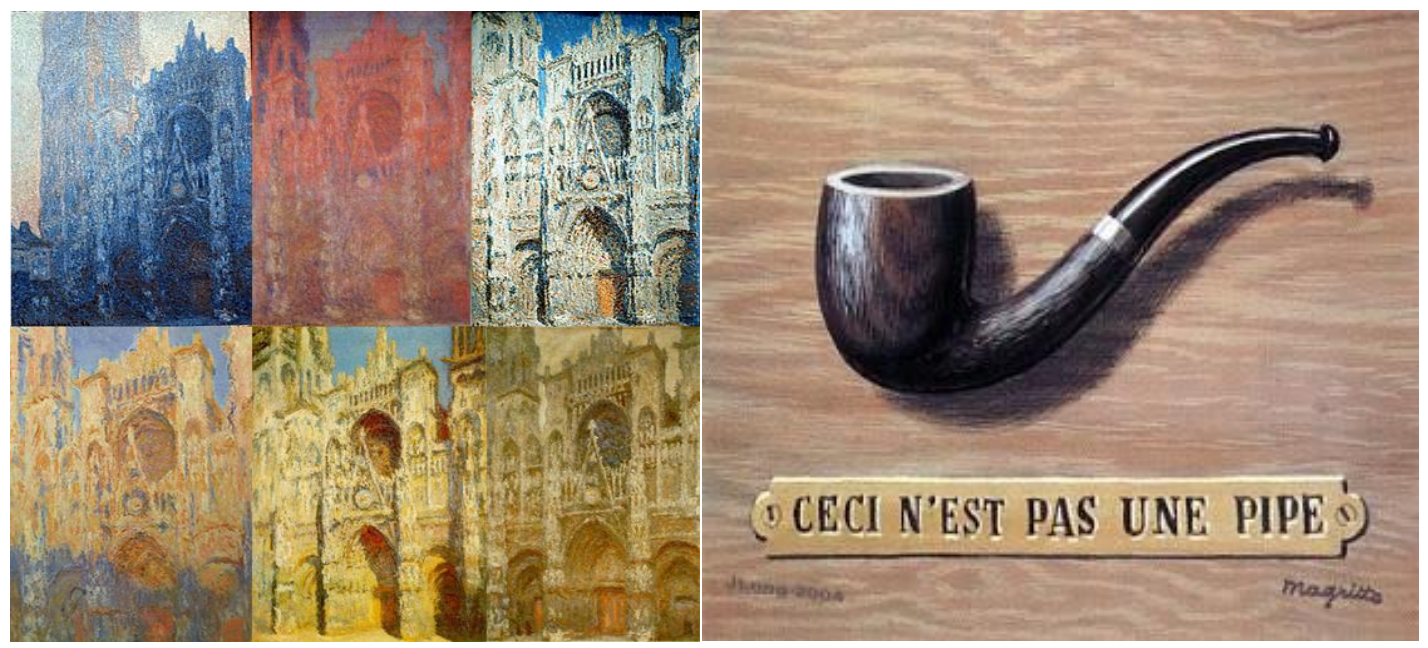

Fonte: Google imagens. Disponível em:

<https://www.google.com/search?q=catedral+de+rouen+claude+monet\&rlz=>;

<https://www.historiadasartes.com/sala-dos-professores/a-traicao-das-imagens-rene-magritte/>.

Acesso em: 04 de jan. 2019.

Monet ao apresentar diferentes imagens de uma mesma fachada - azulada, rosada, esbranquiçada, matizada, amarelada, esverdeada -, capturadas através de um olhar entre suas impressões, a leitura tonalizante de um gigante dogmático cinza, inflectida pelo logos disseminador da luz durante as fases do dia, supera o limite do mero entrever, que não cessa de interrogar o olhar. Magritte põe em crise a escrita e a representação de um objeto para 
fazer emergir outras possibilidades de escrituras inesperadas, insuspeitas, uma desorganização sígnica que estabelece conflitos entre a palavra, a visão, a interpretação e os processos de significação.

Encontram-nos diante de paisagens que nos permitem refletir sobre a forma fluida e irregular do horizonte das políticas de avaliação, por intermédio da leitura da obra de arte, indicando também que estas não são relações objetivamente dadas que parecem o mesmo de todos os ângulos de visão, são constituições perspectivas, inflectidas pelas ações políticas de diferentes atores (Appadurai, 2004).

Assim, como leitora, espectadora e autora de políticas no campo da arte e da educação, em fruição estética com os autores e imagens citadas neste ensaio, aposto no entrelugar mediatório - entre a aura e a ágora - que os sujeitos podem ocupar nessa teia de relações que apresenta uma paisagem cambiante de desejos por uma educação de qualidade. Concluo argumentando que a política de avaliação da Rede Municipal de Educação de Niterói em curso, apurada pelos indicadores de qualidade locais do SAEN, tem se apresentado como uma paisagem reveladora de diferentes tonalidades inflectidas em suas superfícies disjuntivas, engendradas no terreno do indecidível e do imprevisível de cadeias de equivalência formadas em territórios de disputas - uma prática articulatória discursiva que, bem como as obras de arte citadas, se dá na lógica da criação, da negociação e da enunciação.

\section{Notas}

1. Este ensaio é fruto do pós-doutoramento desenvolvido no Programa de Pós-graduação em Educação (ProPEd) da UERJ, sob a supervisão da Professora Doutora Rita de Cassia Prazeres Frangella.

2. Nos anos 60 o astrônomo e matemático alemão August Ferdinand Möbius inventou um objeto topológico, cuja superfície torna-se não orientável ao se ligar a outra extremidade por uma torção, que sugeriu a Escher representá-lo em uma gravura que subverte a representação comum do espaço e do sujeito caminhante - a Tira de Moebius II.

3. O IDEB é um indicador de qualidade educacional que combina informações de desempenho dos alunos do $5^{\circ}$ e do $9^{\circ}$ ano de escolaridade na Prova Brasil com informações sobre rendimento escolar (aprovação, reprovação e abandono).

4. A Rede Municipal de Educação de Niterói é formada por 92 unidades de educação, que atende desde a pré-escola ao $9^{\circ}$ ano do Ensino Fundamental. Conta com profissionais concursados, em algumas situações contratados ou comissionados, que atuam nas escolas e nos setores administrativos e pedagógicos da sede (órgão central).

\section{Referências bibliográficas}

APPADURAI, A. Dimensões Culturais da Globalização: a modernidade sem peias. Tradução Telma Costa. Lisboa: Teorema, 2004.

BHABHA, H. K. O bazar global e o clube dos cavalheiros ingleses: textos seletos de Homi Bhabha. Organização: Eduardo F. Coutinho; introdução: Rita T. Schmidt; tradução: Teresa Dias Carneiro. Rio de Janeiro: Rocco Digital, 2012.

BRASIL, Lei n ${ }^{\circ}$ 13.005, de 25 de junho de 2014. Plano Nacional de Educação - 2014/2024. Disponível em: http://www.planalto.gov.br/ccivil_03/_Ato2011-2014/2014/Lei/L13005.htm. Acesso em: 25 nov. 2018.

BURITY, J. Teoria do discurso e educação: reconstruindo o vínculo entre cultura e política. Revista Teias, v. 11, n. 22, p. 07-29, Rio de Janeiro, maio/agosto 2010. 
DELEUZE, G.; GUATTARI, F. Introdução: Rizoma. In: Mil platôs - capitalismo e esquizofrenia, vol. 1. Tradução: Aurélio Guerra Neto et al. Rio de Janeiro: Ed. 34, 1995 (Coleção TRANS). 1997.

O que é a filosofia? Tradução Bento Prado Jr. e Alberto Alonso Muñoz. 2. ed. Rio de Janeiro: Ed. 34, DERRIDA, J. Força de lei: o fundamento místico da autoridade. Tradução: Leyla Perrone-Moisés. São Paulo: Martins Fontes, 2007.

ERNEST, B. O espelho mágico de M. C. Escher. Tradução: Maria Odete Gonçalves Koller. Berlim: Taschen, 1991.

FRANGELlA, R. P.; BARREIROS, D. R. A. Buscando o sentido de política nos estudos curriculares perspectivas de análise em questão. Constituição Brasileira, Direitos Humanos e Educação. 31 Reunião Anual da ANPED, 2008. Disponível em: http://www.anped.org.br/sites/default/files/gt12-4399-int.pdf. Acesso em: 10 out. 2018.

LACLAU, E.; MOUFFE, C. Hegemonia e estratégia socialista: por uma política democrática radical. São Paulo: Intermeios, 2015.

LOPES, A. C.; CUNHA, E. V. R. da; COSTA, H. H. C. Da recontextualização à tradução: investigando políticas de currículo. Currículo sem fronteiras, v. 13, n.3, p.392-410, set./dez. 2013.

LOPES, A. C. Políticas de currículo em um enfoque discursivo: notas de pesquisa. In: LOPES, A. C.; OLIVEIRA, A. L. A. R. M.; OLIVEIRA, G. G. S. [Orgs]. A teoria do discurso na pesquisa em educação. Recife: Ed. UFPE, 2018a.

Sobre a decisão política em terreno indecidível. In: LOPES, A. C.; SISCAR, Marcos. Pensando a Política em Derrida: responsabilidade, tradução, porvir. São Paulo: Cortez, 2018b.

MACEDO, E. Base Nacional Curricular Comum: novas formas de sociabilidade produzindo sentidos para educação. Revista e-Curriculum, v. 12, n.03, São Paulo, p. 1530-1555, out./nov. 2014.

MOUFFE, C. Por um modelo agonístico de democracia. Dossiê Democracias e Autoritarismos. Revista de Sociologia Política, n. 25, Curitiba, p.11-23, nov. 2005.

NITERÓI. Portaria SEMECT/FME no 005/2015, de 28 de agosto de 2015. Dispõe sobre a regulamentação do Sistema de Avaliação da Educação de Niterói (SAEN) e dá outras providências. Diário Oficial de Niterói. A Tribuna, Niterói, RJ.

RIVERA, T. Ensaio sobre o espaço e o sujeito. Lygia Clark e a psicanálise. Ágora: Estudos em Teoria Psicanalítica. Ágora (Rio J.) vol.11 no.2 Rio de Janeiro July/Dec. 2008. Disponível em: http://www.scielo.br/scielo.php?script=sci_arttext\&pid=S1516-14982008000200004. Acesso em: 5 mai. 2018.

SOUSA, I. M.; SILVA, E. S. da. O olhar em René Magritte. Disponível em: http://psicanaliselacaniana. blogspot.com/2013/11/o-olhar-em-rene-magritte.html. Acesso em: 04 dez. 2018. 


\section{Correspondência}

Maria Cristina Rezende de Campos: Doutora em Memória Social pela UniRio, na linha de pesquisa Memória e Patrimônio, com Pós-Doutorado em Educação pelo ProPEd/UERJ. Assessora de Avaliação Institucional, coordenando a implementação do Sistema de Avaliação da Educação de Niterói (SAEN) da Secretaria Municipal de Educação, Ciência e Tecnologia/Fundação Municipal de Educação de Niterói (SEMECT/FME).

E-mail: cristinarcampos@gmail.com

Texto publicado em Currículo sem Fronteiras com autorização da autora 